Original Article

\title{
The effect of six weeks of sling exercise training on trunk muscular strength and endurance for clients with low back pain
}

\author{
Yu-Lin You' ${ }^{1,2) a}$, Tzu-Kai Su ${ }^{3) a}$, Lin-Jiun Liaw ${ }^{4)}$, Wen-Lan Wu' ${ }^{1)}$ I-Hua Chu' ${ }^{1)}$, \\ LAN-YuEN GuO ${ }^{1)^{*}}$ \\ 1) Department of Sports Medicine, College of Medicine, Kaohsiung Medical University: Kaohsiung \\ City 701, Taiwan \\ 2) Department of Biomedical Engineering, College of Engineering, National Cheng Kung University, \\ Taiwan \\ 3) Division of Physical Medicine and Rehabilitation, Ten-Chen General Hospital, Taiwan \\ 4) Department of Physical Therapy, College of Allied Health, Kaohsiung Medical University, Taiwan
}

\begin{abstract}
Purpose] The purpose of this study was to investigate the effects of 6 weeks sling exercise training for clients with low back pain on the levels of pain, disability, muscular strength and endurance. [Subjects and Methods] Twelve chronic LBP subjects participated in this study. Subjects were randomly divided into a control group and a training group. Subjects in the training group performed sling exercise training for six weeks, and participants in the control group did not perform any exercise. [Results] Pain, disability levels and muscular strength significantly improved in the training group, but not in the control group. The left multifidus showed a significant improvement in muscular endurance, measured as the slope of the median frequency after training. [Conclusion] Six weeks of sling exercise training was effective at reducing pain intensity, and improving the disability level and trunk muscular strength of subjects with low back pain.

Key words: Chronic low back pain, Sling exercise training, Slope of median frequency
\end{abstract}

(This article was submitted Feb. 19, 2015, and was accepted May 18, 2015)

\section{INTRODUCTION}

Lumbar instability is a common symptom and also one of the causes of low back pain. It is usually caused by a neuromuscular control disorder rather than structural instability ${ }^{1)}$. The definition of lumbar segmental instability is decreased stiffness of the spinal motion segments ${ }^{2}$. Previous studies have indicated that lumbar instability is associated with pain possibly ${ }^{3)}$; and it may be due to a defect in spinal segment movement control, leading to compression of the neural structure $^{4,5)}$.

Trunk muscular strength may protect the spine during daily activities ${ }^{6-8)}$. Weakness of the trunk muscles and poor muscular endurance are also characteristics of $\mathrm{LBP}^{9}$ ). The severity of trunk muscular weakness or fatigability may be examined using isokinetic or isometric tests ${ }^{10-12)}$. Numerous studies have investigated the difference in trunk muscular strength and endurance between chronic LBP patients and healthy subjects ${ }^{13,14)}$. Some reported subjects with LBP

a Equal Contribution. *Corresponding author. Lan-Yuen Guo (E-mail: yuen@kmu.edu.tw)

C2015 The Society of Physical Therapy Science. Published by IPEC Inc. This is an open-access article distributed under the terms of the Creative Commons Attribution Non-Commercial No Derivatives (by-ncnd) License $<$ http://creativecommons.org/licenses/by-nc-nd/3.0/>. have significantly less muscular strength and endurance than healthy subjects ${ }^{13,14)}$. This may be explained by LBP clients being unwilling to make maximal effort during the muscular strength test due to pain or fear of injuries ${ }^{15,16)}$.

Previous studies have investigated the trunk muscular activation and muscle fatigue of LBP patients using electromyography (EMG) and compared the results with those of healthy adults. The most frequent site showing pathological changes is the 4th and 5th lumbar vertebrae, where the multifidus muscles are located ${ }^{17)}$. The median frequency of EMG has been used as a fatigue index to compare the back muscular fatigability of the left and right sides between $40 \%$ maximal voluntary contraction (MVC) and $80 \% \mathrm{MVC}$, and the median frequency imbalance was significantly larger in LBP than in healthy subjects ${ }^{16}$.

Regarding exercise training, numerous exercise types have been developed as exercise therapy for clients with LBP, such as hip joint exercises, trunk muscular strengthening exercises, and aquatic exercise ${ }^{18)}$. Lumbar segmental stabilization training is the most popular LBP treatment. It aims to train injured and healthy supporting tissue, facilitate tissue repair and prevent structural weakness from excessive loading ${ }^{19}$. Exercise training for LBP is not only concerned with positional correctness, but also deep muscle and neuromuscular control training. Previous studies have demonstrated that exercise on an unstable surface, such as exercises on a Swiss ball and sling exercise training (S.E.T), 
increases muscular activation levels ${ }^{20-23)}$. The activation levels of the internal and external oblique muscles increased during bridge exercise with vibration training on an unstable surface $^{24)}$. Exercise on an unstable surface challenges the motor control system, the increasing the speed and intensity of lumber stabilizers, contraction and the activation ratio as well as improving muscle activation synergy $19,25,26$ ).

A S.E.T system provides an unstable training condition that increases exercise difficulty ${ }^{22}$. Postnatal women with pelvic pain reported significantly reduced pain, improved physical function and better quality of life after 20 weeks of S.E.T training ${ }^{27)}$. Baseball players with LBP participated in 12 weeks of exercise training, using ultrasound biofeedback training or S.E.T training. The ultrasound biofeedback training comprised stretching and general trunk muscle strengthening under ultrasound monitoring. The ultrasound biofeedback training helped subjects practice and realize how the deep muscles work. The results showed S.E.T training could improve pain, physical function and lumbar instability more significantly than ultrasound biofeedback training ${ }^{28)}$. In general, subjects who suffer from LBP show improved trunk proprioception, physical function and trunk stability after six weeks of S.E.T ${ }^{29)}$.

To the best of our knowledge, most studies have measured the effects of interventions for LBP using functional fitness or a subjective questionnaire. Few studies have measured the effects of exercise intervention on muscular strength and endurance. In addition, due to the possible influence of psychological factors, using the slope of the median frequency may be a relatively objective way of measuring muscular endurance compared to using maintenance time only. Thus, the purpose of this study was to examine the effects of 6 weeks S.E.T for clients with LBP on pain, disability, muscular strength and muscular endurance.

\section{SUBJECTS AND METHODS}

This study recruited chronic LBP patients. They were randomly divided into a control group and a training group. The pain area was located between the lower ribs and gluteus folds, and the pain duration had persisted for at least three months. Subjects who were diagnosed with spondylolisthesis or disc herniation were excluded. The investigators explained the purposes and procedures of the assessment and obtained basic personal information and informed consent before conducting the experiment. The participants provided their written consent to participation and the study was approved by the Kaohsiung Medical University Ethics Committees.

Participants' subjective parameters (pain intensity and disability levels), and objective parameters (muscular strength and endurance) were assessed. Participants in the training group performed stabilization exercise using a S.E.T system for six weeks. Participants in the control group did not perform any exercise intervention. After six weeks, participants, subjective and objective parameters were measured again.

A 10-centimeter visual analog scale was used to measure pain intensity. Low scores represented low pain intensity, and high scores represented high pain intensity.

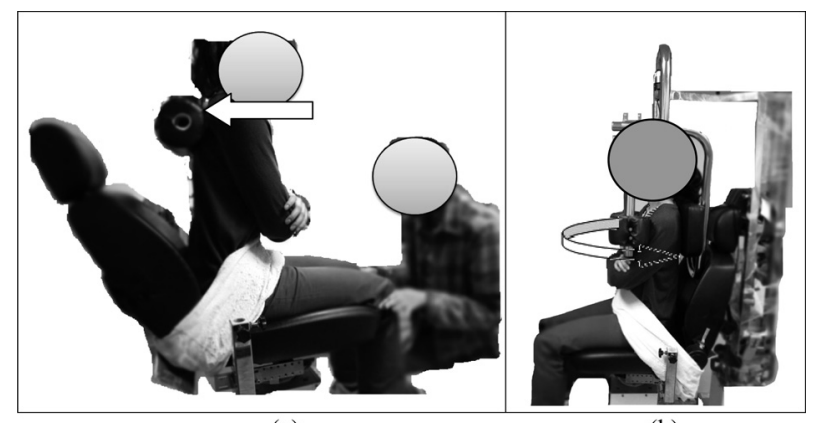

(a)

(b)

Fig. 1. Muscular strength measurements (a) back extension, (b) rotation to left and right

The Chinese version of the Oswestry disability scale for LBP was used to measure the disability level ${ }^{30}$. This questionnaire has 10 items assessing pain and disability. Each item is scored from 0 to 5, with higher the scores indicating greater disability. The maximum score for this questionnaire is 50 points, and the raw scores are converted to percentages. According to Fairbank ${ }^{31)}$, 0-20\% represents mild disability, $21-40 \%$ represents moderate disability, $41-60 \%$ represents severe disability, $61-80 \%$ means most physical functions are impaired by back pain, and it is classified as disabled, and $81-100 \%$ means the subject is bed-bound.

The muscular strength assessment was measured by a custom-designed muscular strength dynamometer. Subjects were instructed to carry out the trunk extension and rotation to the left and right in a sitting position. For each movement they aimed to exert maximal voluntary isometric contraction for 5 seconds in three trials (Fig. 1). During the trunk flexion and extension test, the torque sensor was placed on the left of the body with its height parallel to the iliac crest.

For the trunk extension test, a fixed bar was set on the spine at the height of the scapula to fix the trunk, and an investigator applied a strength with force along the femoral bone. The torque sensor was placed on the head to measure trunk rotation the fixed bar set at the height of the sternal notch. Velcro was used to fix the pelvis during all tests.

Subjects rested for ten minutes after the maximal muscular strength test, and then carried out the endurance test at about $52 \%$ MVIC test ${ }^{32)}$ in one trial. Subjects performed trunk extension and sustained the contraction until they could not maintain the standard testing posture, their hand touched the bed, or the posture was sustained for 240 seconds. The investigators recorded the time the subject sustained the posture, and the change in the median frequency slope was used as an index of fatigue. Each subject performed this test one time.

Participants in the training group attended an exercise course of three sessions a week with each session comprising 30 minutes of training and 10 minutes of warm up.

In the training program, participants had to hold the end position for 8-10 seconds in 12-15 repetitions of each exercise. The exercise intensity was adjusted by the distance from the point of sling suspension and the distance between the slings and the bed. The repetitions and intensity of exercise were gradually increased. Investigators considered 


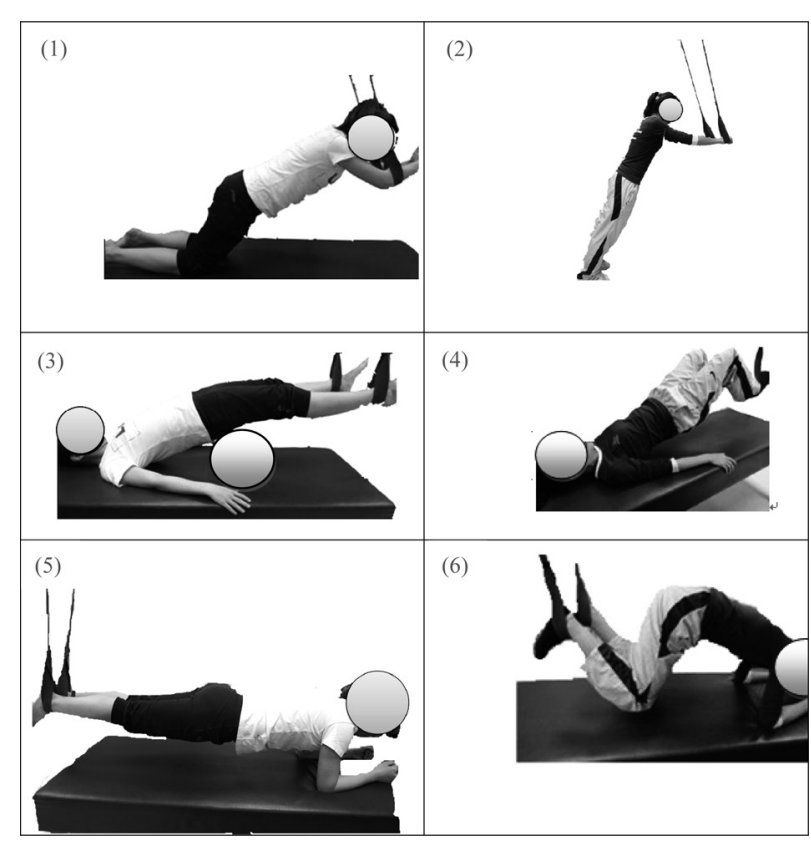

Fig. 2. Exercise training programs

1) Subjects knelt with their arms in the slings and gradually extended their arms while keeping their arms straight.

2) Subjects stood with their hands in the slings and gradually extended their arms while keeping their backs straight.

3) Subjects lay on the bed with their ankles in the slings and executed a bridging exercise.

4) Subjects lay on the bed with their ankles in the slings, and executed a bridge. Then, they gradually flexed their knees to increase the instability.

5) Subjects lay prone on the bed with their ankles in the slings. Then, they executed the plank exercise.

6) Subjects lay prone on the bed with their ankles in the slings. They executed the plank exercise, then gradually flexed their knees to increase the instability.

the fitness levels differed between the participants, thus, the exercise prescriptions were individually decided with different exercise maintenance times and repetitions in the initial training session. Investigators instructed participants to perform a pelvic backward tilt and keep their back straight during exercise to prevent injury through excessive loading of the lumbar spine during exercise.

Exercise (1): participants were instructed to flex the elbow to 90 degrees and kneel on the bed under the sling point. The forearms were put in straps and the body was extended. Exercise (2): participants stood on the floor and under the sling point. The hands were put in the straps and the body was extended. Participants lay supine on the bed with their ankles under the sling point. Exercise (3): the straps were 30 centimeters apart from the bed. Participants were instructed to carry out the bridge exercise. Exercise (4): participants lay supine on the bed with the ankles under the sling point. The straps were 30 centimeters apart from the bed. Participants were instructed to carry out the bridge exercise combined with knee flexion. Exercise (5): participants lay prone on the bed and the ankles were under the sling point. Straps were set at the height of the participants' upper arm to make the
Table 1. Characteristics of the subjects

\begin{tabular}{lccc}
\hline & $\begin{array}{c}\text { Control group } \\
(\mathrm{N}=5)\end{array}$ & $\begin{array}{c}\text { Training group } \\
(\mathrm{N}=7)\end{array}$ & \\
\hline Age $(\mathrm{yrs})$ & $27.6(6.7)$ & $27.6(5.6)$ & - \\
Height $(\mathrm{m})$ & $1.65(0.07)$ & $1.60(0.04)$ & - \\
Body weight $(\mathrm{kg})$ & $57.6(12.2)$ & $57.0(9.9)$ & - \\
\hline
\end{tabular}

body parallel to the bed during exercise. The participants supported their body with their forearms and ankles. Exercise (6): participants lay prone on the bed and the ankles were under the sling point. Straps were set as high as the participants' upper arm to make the body parallel to the bed during the exercise, and the participants supported their body with their forearms and ankles combined with knee flexion. All the exercise programs are shown in Fig. 2.

Investigators calculated the mean of maximal torque of 10 consecutive data minus the mean baseline torque for 10 consecutive data to calibrate the error. The 10 consecutive data of maximal torque were chosen as the 5 data before the maximal value and the 5 data after maximal value. The value divided by the lever arm was used to obtain the force value. Muscular strength was normalized to subjects' body weight.

The trunk muscular endurance was measured during extension, and the effects of S.E.T on trunk muscular endurance. Fatigue was assessed using the slope of each back muscle.

The sampling rate of the EMG system was $1,500 \mathrm{~Hz}$. Fast Fourier transform (512 point, window processing) were used to convert the time-domain signal to the frequency domain and the median frequency was calculated ${ }^{13)}$. The calculated median frequency values were fitted using a first-order curve approximation to calculate the slope of the median frequency. A positive slope indicates neuromuscular fatigue did not build up; a negative slope indicates neuromuscular fatigue is present and a more negative slope indicates a higher level of neuromuscular fatigue ${ }^{16)}$. The median frequency slope calculation was performed using Matlab (Version R2007b MathWorks Inc., Natwick MA, USA).

Wilcoxon's rank test was used to compare the differences in parameters between pre-and post-intervention. The $\alpha$ level was chosen as 0.05 , the level of significance. The statistical analyses were performed using JMP statistical software (Version 9.0.0 SAS institute Inc.).

\section{RESULTS}

This study recruited 16 LBP subjects, who were randomly assigned to the training group and the control group. Nine were in the training group and the remaining seven were in the control group. However, two subjects in the training group dropped out of the study due to their work pattern changing, which made them unable to participate in the training sessions. In addition, two subjects in the control group dropped out of the study due to personal reasons. Thus, the total number of subjects was 12 , with seven in the training group and the remaining five in the control group. The characteristics of the subjects are listed in Table 1. 
Table 2. Values of the subjective parameters of each group at pre-and post-training

\begin{tabular}{lcccccc}
\hline & \multicolumn{3}{c}{ Control group $(\mathrm{N}=4)$} & \multicolumn{3}{c}{ Training group $(\mathrm{N}=7)$} \\
\cline { 2 - 7 } & Pre training & Post training & Pre training & Post training & \\
\hline Pain intensity & $3.75(0.87)$ & $2.38(1.03)$ & - & $4.29(1.44)$ & $1.33(1.17)$ & $*$ \\
Oswestry (\%) & $19.00(16.20)$ & $18.50(11.82)$ & - & $14.29(3.90)$ & $8.86(6.41)$ & $*$ \\
\hline \multicolumn{2}{l}{ The Wilcoxon rank test was used to compare the pre-and post-training values of each group, and }
\end{tabular}

$*$ significant difference $(\mathrm{p}<0.05)$.

Table 3. The values of muscular strength each group at pre-and post-training

\begin{tabular}{lcccccc}
\hline & \multicolumn{3}{c}{ Control group $(\mathrm{N}=5)$} & \multicolumn{3}{c}{ Training group $(\mathrm{N}=7)$} \\
\cline { 2 - 7 } & Pre training & Post training & & Pre training & Post training & \\
\hline Extension $(\mathrm{kg}-\mathrm{m} / \mathrm{BW})$ & $0.57(0.10)$ & $0.54(0.12)$ & - & $0.39(0.15)$ & $0.59(0.14)$ & $*$ \\
Rotation to right $(\mathrm{kg}-\mathrm{m} / \mathrm{BW})$ & $0.37(0.12)$ & $0.35(0.12)$ & - & $0.30(0.10)$ & $0.41(0.08)$ & $*$ \\
Rotation to left $(\mathrm{kg}-\mathrm{m} / \mathrm{BW})$ & $0.43(0.12)$ & $0.38(0.04)$ & - & $0.27(0.11)$ & $0.38(0.08)$ & $*$ \\
\hline
\end{tabular}

The Wilcoxon rank test was used to compare the pre-and post-training values of each group, and * significant differences $(\mathrm{p}<0.05)$.

This study used a visual analog scale to measure the pain intensity. Higher scores on this scale indicated higher pain intensity. The pain intensity of the control group and training group before training was $3.75( \pm 0.87)$ and 4.29 $( \pm 1.44)$, respectively, with no significant difference between the groups.

In the control group, the pain intensity had reduced after six weeks, but it did not improve significantly (Table 2). In the training group, after six weeks of training, pain intensity was reduced to $1.33( \pm 1.17) \mathrm{cm}$, and there was a significant improvement in pain intensity between pre- and post-training $(\mathrm{p}<0.05)$ (Table 2).

The training group showed a slightly higher disability level than the control group at the baseline assessment, but there was no statistically significant difference between the groups (Table 2).

After six weeks, there was no significant improvement in the Oswestry disability index for the control group (Table 2). The disability level in the training group before training was $14.29( \pm 3.90)$ percent, and after training, the disability level was significantly lower at $8.86( \pm 6.41)$ percent $(\mathrm{p}<0.05)$ (Table 2).

A comparison of baseline measurements between the groups showed the muscular strengths in extension of the control and training groups were $0.57( \pm 0.10) \mathrm{kg}-\mathrm{m} / \mathrm{BW}$ and $0.39( \pm 0.15) \mathrm{kg}-\mathrm{m} / \mathrm{BW}$, that of rotation to the right was $0.37( \pm 0.12) \mathrm{kg}-\mathrm{m} / \mathrm{BW}$ and $0.30( \pm 0.10) \mathrm{kg}-\mathrm{m} / \mathrm{BW}$, and that of rotation to left and $0.43( \pm 0.12) \mathrm{kg}-\mathrm{m} / \mathrm{BW} 0.27( \pm 0.11)$ $\mathrm{kg}-\mathrm{m} / \mathrm{BW}$, respectively. The control group had greater absolute muscular strength than the training group in extension and rotation to the left and right. However, there were no significant differences between the groups.

In the control group, extensor and rotator muscular strength had slightly decreased after six weeks without training. However, the results were not significantly different (Table 3). In the training group, muscular strength improved after six weeks training. The absolute extensor muscular strength was $0.39( \pm 0.15) \mathrm{kg}-\mathrm{m} / \mathrm{BW}$ before training, and it increased to $0.59( \pm 0.14) \mathrm{kg}-\mathrm{m} / \mathrm{BW}$ after six weeks of S.E.T $(\mathrm{p}<0.05)$ (Table 3$)$. The results showed muscular strength of rotation to the right was $0.30( \pm 0.10) \mathrm{kg}-\mathrm{m} / \mathrm{BW}$ before training, and it increased significantly to $0.41( \pm 0.08) \mathrm{kg}-\mathrm{m} / \mathrm{BW}$ after six weeks of training $(\mathrm{p}<0.05)$. The muscular strength of rotation to the left was $0.27( \pm 0.11) \mathrm{kg}-\mathrm{m} / \mathrm{BW}$ before training, and it increased significantly to $0.38( \pm 0.08) \mathrm{kg}-\mathrm{m} /$ BW $(\mathrm{p}<0.05)$ after 6 weeks of training (Table 3$)$.

Comparison of the slope of the median frequency between the control and training group showed no significant difference at baseline for all the muscles measured. In the control group, the slope of the median frequency for all muscle sites showed no improvement after six weeks.

The slope of median frequency in the training group showed a significant improvement on the left side of the multifidus after training (the slopes at baseline and posttraining were -0.11 and -0.08 , respectively) $(\mathrm{p}<0.05)$ (Table 4). However, the other muscle sites did not show any significant changes after training.

\section{DISCUSSION}

This study found the subjective parameters were significantly reduced by training. These findings are similar to those of previous studies ${ }^{28,29}$. Chu reported the effects of S.E.T on baseball players who suffered from LBP. That study recruited 12 LBP baseball players, and carried out three stages of exercise training. In the first stage, ultrasound was used as a biofeedback in the training of deep muscle contraction. The second stage was the trunk muscular strengthening course, and the third stage was stabilization exercise training on slings. Pain intensity was significantly reduced after S.E.T, but it was not apparent at trunk muscular strengthening stage ${ }^{28)}$. That is, the S.E.T was more effective at reducing pain than the trunk muscular strengthening course for LBP patients. Chang et al. also investigated the effects of six weeks of S.E.T on LBP patients ${ }^{29)}$. They found that the disability level, functional fitness and trunk proprioception improved after six weeks of training. The present study found the disability level reduced after training. The 
Table 4. Median frequency comparison of the values of each group at pre-and post-training

\begin{tabular}{|c|c|c|c|c|c|c|}
\hline \multirow{2}{*}{$\begin{array}{l}\text { Slope of MF on } \\
\text { each muscle site }\end{array}$} & \multicolumn{3}{|c|}{ Control group $(\mathrm{N}=5)$} & \multicolumn{3}{|c|}{ Training group $(\mathrm{N}=7)$} \\
\hline & Pre training & Post training & & Pre training & Post training & \\
\hline L-ES & $-0.04(0.02)$ & $-0.04(0.02)$ & - & $-0.06(0.01)$ & $-0.05(0.01)$ & - \\
\hline R-ES & $-0.04(0.01)$ & $-0.05(0.03)$ & - & $-0.04(0.01)$ & $-0.05(0.02)$ & - \\
\hline L-MF & $-0.06(0.03)$ & $-0.06(0.03)$ & - & $-0.11(0.01)$ & $-0.08(0.01)$ & * \\
\hline R-MF & $-0.06(0.04)$ & $-0.05(0.04)$ & - & $-0.11(0.02)$ & $-0.08(0.01)$ & - \\
\hline
\end{tabular}

The Wilcoxon rank test was used to compare the pre-and post-training values of each group, and * significant differences $(\mathrm{p}<0.05)$.

(Units: Hz/s)

L-ES: Left side erector spinae; R-ES: Right side erector spinae; L-MF: Left side multifidus; R-MF: Right side multifidus

studies of Chang and Chu et al. both demonstrate that six weeks of S.E.T is effective at reducing the pain intensity and disability levels of LBP patients. However, these two studies did not measure the pain intensity and disability level simultaneously ${ }^{28,29)}$, and they did not utilize a control group.

In the present study, there was a significant improvement in muscular strength and endurance after six weeks training, a result which is similar to those of previous studies. Bronfort et al. compared muscular strength among three different types of exercise mode. They found that trunk strengthening exercise combined with spinal manipulation and trunk strengthening exercise combined with non-steroid anti-inflammatory drugs elicited greater improvements than spinal manipulation combined with the trunk stretching exercise $^{32)}$. They also found a significant improvement in trunk muscular strength at the 11th week. According to a previous study ${ }^{18)}$, a significant increase in the activation of the rectus abdominis was elicited by exercising on a Swiss ball indicating that exercise on an unstable surface had increased the difficulty of exercise and the muscular activation. Chok et al. measured the maintenance time of trunk extensor endurance as the training outcome. In their study, sub-acute LBP patients were randomly assigned to a control group or a experiment group. The experimental group attended exercise training for six weeks, but the control group did not. Both groups received back care and hot packs for six weeks. After the exercise training, the maintenance time of trunk extensor endurance was not a significantly different between the two groups, despite the experimental group having better maintenance time of trunk extensor endurance than the control group at weeks 3 and $6^{33)}$. In contrast, Bronfort et al. found that subjects in the trunk muscular strength exercise groups showed greater improvements in back extensor endurance than the other two groups at week 11 , but not at week $5^{32}$.

The slope of the median frequency indicates neuromuscular fatigue and a positive slope indicates the absence of neuromuscular fatigue; a negative slope indicates the presence of neuromuscular fatigue, and a more negative slope indicates a higher level of neuromuscular fatigue. The present study found that the slope of the median frequency of the multifidus muscles was a more negative value at baseline than after training. This result means the multifidus muscles had a lower level of neuromuscular fatigue in the endurance test after training. In the study of Oddsson et al. ${ }^{16)}$, the LBP group carried out trunk extensor endurance tests at $40 \%$ and $80 \%$ MVC in a standing position. Their results of that study show the slope of the median frequency at $40 \%$ MVC ranged from -0.03 to $0.26(\mathrm{~Hz} / \mathrm{s})$, and the median value was $0.035(\mathrm{~Hz} / \mathrm{s})$, indicating neuromuscular fatigue did not accumulate. In that study, subjects performed $40 \% \mathrm{MVC}$, as in our study (about 52\% MVC), but the testing position in that study was standing, which differed from our study. To the best of our knowledge, most studies which have measured trunk extensor endurance as an exercise outcome have used the maintenance time rather than the slope of the median frequency. Few studies have used the slope of median frequency to compare the difference between healthy subjects and the LBP subjects. Our present study, used the slope of the median frequency, and found there was a significantly more negative slope for the left multifidus at baseline in pretraining for the training group, indicating a higher level of neuromuscular fatigue at the pre-training measurement than at the post-training measurement. The training group had a border-line significantly higher level of neuromuscular fatigue at the pre training measurement for the right multifidus relative to the post-training measurement.

The sample size of this study was relatively small. Twelve patients participated in this study, and there were randomly allocated to the training group and the control group, with seven subjects in the training group and five subjects in the control group. A trail with $80 \%$ power and a level of significance of $5 \%$ (two tailed) was calculated to require approximately 20 patients in the training group to detect significant differences between pre- and post-training. Another limitation of this study was that the training lasted for only 6 weeks. This may not have been long enough time to improve local muscular endurance. In our results, the slope of the median frequency showed a significant improvement for the left side multifidus but not for the other back muscles. Prolonged exercise training may lead to greater improvements in muscular endurance of the other back muscles.

Further research should involve a greater number of participants. The exercise program should be prolonged for chronic LBP patients to try to achieve greater improvement. The slope of the median frequency for objectively measures neuromuscular fatigue and should be considered as a parameter for assessing the training effects. 


\section{ACKNOWLEDGEMENT}

This work was supported by the Ten Chan General Hospital and KMU Joint Research Project (ST102007), Taiwan.

\section{REFERENCES}

1) Nachemson A: Lumbar spine instability. A critical update and symposium summary. Spine, 1985, 10: 290-291. [Medline] [CrossRef]

2) Farfan HF, Cossette JW, Robertson GH, et al.: The effects of torsion on the lumbar intervertebral joints: the role of torsion in the production of disc degeneration. J Bone Joint Surg Am, 1970, 52: 468-497. [Medline]

3) Bogduk N: Clinical anatomy of the lumbar spine and sacrum. Edinburgh Churchill Livingstone, 1997

4) Panjabi MM: The stabilizing system of the spine. Part I. Function, dysfunction, adaptation, and enhancement. J Spinal Disord, 1992, 5: 383-389, discussion 397. [Medline] [CrossRef]

5) Panjabi MM: The stabilizing system of the spine. Part II. Neutral zone and instability hypothesis. J Spinal Disord, 1992, 5: 390-396, discussion 397. [Medline] [CrossRef]

6) Cady LD, Bischoff DP, O'Connell ER, et al.: Strength and fitness and subsequent back injuries in firefighters. J Occup Med, 1979, 21: 269-272. [Medline]

7) Caldwell JS, McNair PJ, Williams M: The effects of repetitive motion on lumbar flexion and erector spinae muscle activity in rowers. Clin Biomech (Bristol, Avon), 2003, 18: 704-711. [Medline] [CrossRef]

8) Cairns MC, Foster NE, Wright C: Randomized controlled trial of specific spinal stabilization exercises and conventional physiotherapy for recurrent low back pain. Spine, 2006, 31: E670-E681. [Medline] [CrossRef]

9) Hides JA, Richardson CA, Jull GA: Multifidus muscle recovery is not automatic after resolution of acute, first-episode low back pain. Spine, 1996, 21: 2763-2769. [Medline] [CrossRef]

10) Mayer T, Gatchel R, Betancur J, et al.: Trunk muscle endurance measurement. Isometric contrasted to isokinetic testing in normal subjects. Spine, 1995, 20: 920-926, discussion 926-927. [Medline] [CrossRef]

11) Ebenbichler GR, Oddsson LI, Kollmitzer J, et al.: Sensory-motor control of the lower back: implications for rehabilitation. Med Sci Sports Exerc, 2001, 33: 1889-1898. [Medline] [CrossRef]

12) Keller A, Hellesnes J, Brox JI: Reliability of the isokinetic trunk extensor test, Biering-Sørensen test, and Astrand bicycle test: assessment of intraclass correlation coefficient and critical difference in patients with chronic low back pain and healthy individuals. Spine, 2001, 26: 771-777. [Medline] [CrossRef]

13) Newton M, Thow M, Somerville D, et al.: Trunk strength testing with isomachines. Part 2: Experimental evaluation of the Cybex II Back Testing System in normal subjects and patients with chronic low back pain. Spine, 1993, 18: 812-824. [Medline] [CrossRef]

14) Latimer J, Maher CG, Refshauge K, et al.: The reliability and validity of the Biering-Sorensen test in asymptomatic subjects and subjects reporting current or previous nonspecific low back pain. Spine, 1999, 24: 2085-2089, discussion 2090. [Medline] [CrossRef]

15) Larivière C, Arsenault AB, Gravel D, et al.: Surface electromyography assessment of back muscle intrinsic properties. J Electromyogr Kinesiol, 2003, 13: 305-318. [Medline] [CrossRef]

16) Oddsson LI, De Luca CJ: Activation imbalances in lumbar spine muscles in the presence of chronic low back pain. J Appl Physiol 1985, 2003, 94: 1410-1420. [Medline] [CrossRef]

17) Huang $\mathrm{Q}$, Zhang $\mathrm{Y}$, Li D, et al.: The evaluation of chronic low back pain by determining the ratio of the lumbar multifidus muscle cross-sectional areas of the unaffected and affected sides. J Phys Ther Sci, 2014, 26: 1613-1614. [Medline] [CrossRef]

18) Lee SW, Kim SY: Effects of hip exercises for chronic low-back pain patients with lumbar instability. J Phys Ther Sci, 2015, 27: 345-348. [Medline] [CrossRef]

19) McGill SM: Low back exercises: evidence for improving exercise regimens. Phys Ther, 1998, 78: 754-765. [Medline]

20) Marshall PW, Murphy BA: Core stability exercises on and off a Swiss ball. Arch Phys Med Rehabil, 2005, 86: 242-249. [Medline] [CrossRef]

21) Imai A, Kaneoka K, Okubo Y, et al.: Trunk muscle activity during lumbar stabilization exercises on both a stable and unstable surface. J Orthop Sports Phys Ther, 2010, 40: 369-375. [Medline] [CrossRef]

22) Saliba SA, Croy T, Guthrie R, et al.: Differences in transverse abdominis activation with stable and unstable bridging exercises in individuals with low back pain. N Am J Sports Phys Ther, 2010, 5: 63-73. [Medline]

23) Petrofsky JS, Batt J, Nicceta D, et al.: Core muscle activity during exercise on a mini stability ball compared with abdominal crunches on the floor and on a swiss ball. J Appl Res, 2007, 7: 255-272.

24) Park J, Lee S, Hwangbo G: The effects of a bridge exercise with vibration training and an unstable base of support on lumbar stabilization. J Phys Ther Sci, 2015, 27: 63-65. [Medline] [CrossRef]

25) Vera-Garcia FJ, Grenier SG, McGill SM: Abdominal muscle response during curl-ups on both stable and labile surfaces. Phys Ther, 2000, 80: 564-569. [Medline]

26) Riemann BL, Myers JB, Lephart SM: Comparison of the ankle, knee, hip, and trunk corrective action shown during single-leg stance on firm, foam, and multiaxial surfaces. Arch Phys Med Rehabil, 2003, 84: 90-95. [Medline] [CrossRef]

27) Stuge B, Veierød MB, Laerum E, et al.: The efficacy of a treatment program focusing on specific stabilizing exercises for pelvic girdle pain af ter pregnancy: a two-year follow-up of a randomized clinical trial. Spine, 2004, 29: E197-E203. [Medline] [CrossRef]

28) Chu JH: Effects of Lumbar stabilization for Baseball Fielders with Low Back Pain. Master Thesis, National Yang-Ming University, 2006.

29) Chang HY, Ho SC, Lin $\mathrm{CH}$, et al.: The effects of 6-week sling exercise training on patients with chronic low back pain. Chung Shan Med J, 2011, 22: 43-51.

30) Chow JH, Chan CC: Validation of the Chinese version of the Oswestry Disability Index. Work, 2005, 25: 307-314. [Medline]

31) Fairbank JC, Couper J, Davies JB, et al.: The Oswestry low back pain disability questionnaire. Physiotherapy, 1980, 66: 271-273. [Medline]

32) Bronfort $\mathrm{G}$, Goldsmith $\mathrm{CH}$, Nelson $\mathrm{CF}$, et al.: Trunk exercise combined with spinal manipulative or NSAID therapy for chronic low back pain: a randomized, observer-blinded clinical trial. J Manipulative Physiol Ther, 1996, 19: 570-582. [Medline]

33) Chok B, Lee R, Latimer J, et al.: Endurance training of the trunk extensor muscles in people with subacute low back pain. Phys Ther, 1999, 79: 1032-1042. [Medline] 